\title{
Evaluation of endoscopic mucosal resection and endoscopic submucosal dissection in submucosal lesions of the colon and rectum
}

\author{
Şükrü Çolak, Bünyamin Gürbulak, Ekrem Çakar, Hasan Bektaş \\ Department of General Surgery, Istanbul Training and Research Hospital, Istanbul, Turkey
}

Videosurgery Miniinv 2018; 13 (4): 448-453

DOI: https://doi.org/10.5114/wiitm.2018.78829

\begin{abstract}
Introduction: Endoscopic mucosal resection (EMR) and endoscopic submucosal dissection (ESD) are commonly used for the minimally invasive treatment of submucosal lesions of the gastrointestinal tract.

Aim: To evaluate the safety, efficacy, outcome and recurrence rate of EMR and ESD for mucosal and submucosal lesions in the colon and rectum.

Material and methods: Records of 26 patients who underwent ESD and EMR for mucosal and submucosal lesions in the colon and rectum between January 2013 and March 2018 in our endoscopy unit were retrospectively reviewed.

Results: $A$ total of 26 patients ( 6 female and 20 male) were evaluated. The mean age of the patients was $58.03 \pm 15.19$ (21-80). Fifteen patients underwent ESD and EMR for rectal lesions. Tubular adenomas were found in 3 of these patients, tubulo-villous adenomas in 2, inflammatory polyps in 1, neuroendocrine tumors in 2 and carcinomas in 7 (intramucosal, in-situ and invasive). Eleven patients underwent ESD and EMR for colonic lesions. Villous adenomas were found in 2 of these patients, tubular adenoma showing dysplasia in 2, tubulo-villous adenomas showing dysplasia in 1 and carcinoma (in-situ, invasive and intramucosal) in 6. Two lesions were resected with secondary transanal local excision to obtain free margins. The follow-up period was 3 to 48 months and no recurrence was observed.

Conclusions: The EMR and ESD are reliable minimally invasive techniques with a low rate of complications and short hospital stay in the treatment of colon and rectal lesions, including early stage carcinomas of different size and morphology.
\end{abstract}

Key words: endoscopic submucosal dissection, colorectal submucosal lesion, endoscopic mucosal resection.

\section{Introduction}

Endoscopic mucosal resection (EMR) was first used by Tada et al. to obtain more biopsy material from gastric lesions [1]. It was introduced as a treatment modality for stomach cancer, which can be diagnosed in the early period thanks to the increase of experience of endoscopists and developments in technology. This method has become an alternative to surgical resection because it is less invasive and more comfortable for the patient, with lower costs and reliable results. Over time, indications for endoscopic resection were accepted as options for treatment of other premalignant or early stage malign tumors of the gastrointestinal tract, and then the indications for endoscopic treatment were expanded to include superficial lesions (elevated and depressed types) [2].

Initially, EMR was widely accepted as a treatment of resection of large and flat gastrointestinal tumors 
as well as superficially located premalign and malignant lesions of the colon and rectum $[3,4]$.

However, since lesions larger than $2 \mathrm{~cm}$ are difficult to remove completely, endoscopic submucosal dissection (ESD) has been developed [3-5].

We performed EMR and ESD in 26 patients with superficial lesions of the colon and rectum in our endoscopy unit between January 2003 and March 2018.

The locations, sizes and macroscopic classification of lesions, excision methods and materials used for excision, complications and histopathological findings, methods used in patient follow-up and recurrence rates were evaluated retrospectively.

\section{Aim}

In this study we aimed to evaluate the safety, efficacy, outcome and recurrence rate of EMR and ESD for mucosal and submucosal lesions of the colon and rectum.

\section{Material and methods}

Between January 2013 and March 2018, EMR was performed in 11 patients and ESD in 4 patients with rectal involvement. Only 10 patients with colonic involvement underwent EMR and 1 patient underwent ESD.

All endoscopic procedures were performed under sedo-analgesia. Detailed informed consent was obtained from all of the patients. All patients' vital signs were monitored during the procedure.

Before EMR, free margin of lesions were marked by hot forceps. Subsequently, starting from the proximal lesion, adrenaline and a marker diluted $1 / 10$ with $\mathrm{NaCl}$ solution were applied to the submucosal area to raise the lesion from the colon mucosa. Then, mucosal resection was performed with the help of electrocautery.

Before ESD, free margin of lesions were marked by hot forceps. Subsequently, starting from the proximal lesion, adrenaline and a marker diluted 1/10 with $\mathrm{NaCl}$ solution or sodium hyaluronate were applied to the submucosal area to raise the lesion from the colon mucosa. After the elevation of the lesion from the mucosa, the lesions were removed by submucosal dissection with special cutting tools produced for this purpose, such as the insulation-tipped (IT) knife.

\section{Statistical analysis}

Descriptive statistical methods such as mean \pm standard deviation (SD) and/or median (min- $\max$ ), frequency and percentage were used in the evaluation of the data. Statistical analysis was performed with the SPSS software package for Windows (Statistical Package for Social Sciences, version 17.0, SPSS Inc., Chicago, Illinois, USA).

\section{Results}

The mean age of the patients was $58.03 \pm 15.19$ (21-80). Six of the patients were female and 20 were male. Paris classification was used for classification according to appearance of lesions. The distribution of localized lesions in the colon according to the Paris classification was such that 7 were Ip, 2 were Is, and 2 were Ila. The distribution in the rectum was such that 4 were Ip, 6 were Is and 5 were Ila.

Table I shows the location, age, gender, procedure and pathological diagnosis of the lesions in patients who underwent EMR and ESD for colonic lesions. The mean age of patients who had colonic lesions was $59.27 \pm 12.78$ (40-73).

After EMR of 2 sessile polyps in the transverse and sigmoid colon, the pathological diagnosis of one was in situ carcinoma with dysplasia continuing on the surgical margin and that of the other was tubulovillous adenoma with positive surgical margin; secondary EMR was performed and a free surgical margin was achieved.

The ESD was performed on 5 patients and EMR was performed on 10 patients with lesions in the rectum. Before the ESD procedure, the depth of the lesion was evaluated by transrectal ultrasound.

Table II shows the location, age, gender, procedure and pathological diagnosis of the lesions in patients who underwent EMR and ESD for rectal lesions. The mean age of patients who had rectal lesions was $57.13 \pm 27.13(21-80)$.

After EMR of 2 lesions in the rectum, due to the continuity of the lesions at the surgical margin, transanal local excision (TALE) was performed and a negative surgical margin was achieved. The pathological examination of these lesions yielded the diagnosis of in situ carcinoma in one and neuroendocrine tumor in the other.

The median size of the colorectal lesions was $2(1.2-3) \mathrm{cm}$ and that of the rectal lesions was 2 (1.24) $\mathrm{cm}$. Complications were not observed in patients with EMR. During ESD, bleeding control was provided in 1 patient by clipping. The mean duration of EMR was 33 (20-45) min while that of ESD was $60(45-75) \mathrm{min}$. 
Table I. Location, age, gender, procedure and pathological diagnosis of lesions in patients who underwent EMR and ESD for colonic lesions

\begin{tabular}{|lcccc|}
\hline Age/gender & Localization & Lesion size $[\mathrm{cm}]$ & Procedure & Pathology \\
\hline 45/M & Transverse colon & $1.5 \times 1.4$ & EMR & Carcinoma in situ \\
\hline 52/M & Transverse colon & $1.5 \times 0.9$ & EMR & Villous adenoma \\
\hline $40 / \mathrm{M}$ & Transverse colon & $1.2 \times 0.9$ & Polypectomy/EMR & Carcinoma in situ \\
\hline $63 / \mathrm{M}$ & Left colon & $2 \times 0.9$ & EMR & Carcinoma in situ \\
\hline 40/F & Sigmoid colon & $3 \times 1.8$ & Piecemeal EMR & Tubulo-villous adenoma-HGD \\
\hline $70 / \mathrm{M}$ & Sigmoid colon & $3 \times 1.1$ & EMR & Carcinoma in situ \\
\hline $72 / \mathrm{F}$ & Sigmoid colon & $2 \times 1.8$ & EMR & Intramucosal carcinoma \\
\hline $73 / \mathrm{M}$ & Sigmoid colon & $3 \times 1.9$ & EMR & Intramucosal carcinoma \\
\hline $62 / \mathrm{M}$ & Sigmoid colon & $3 \times 1.9$ & Piecemeal EMR & Villous adenoma-HGD \\
\hline $65 / \mathrm{K}$ & Rectosigmoid junction & $3 \times 2.4$ & EMR & Tubular adenoma \\
\hline $70 / \mathrm{M}$ & Rectosigmoid junction & $1.5 \times 1.2$ & ESD & Tubular adenoma-LGD \\
\hline
\end{tabular}

HGD - high grade dysplasia, LGD - low grade dysplasia.

Table II. Location, age, gender, procedure and pathological diagnosis of lesions in patients who underwent EMR and ESD for rectal lesions

\begin{tabular}{|llccc|}
\hline Age/gender & Localization & Lesion size $[\mathrm{cm}]$ & Procedure & Pathology \\
\hline 80/M & Proximal rectum & $3 \times 1.3$ & ESD & Tubular adenoma \\
\hline $42 / \mathrm{F}$ & Middle rectum & $1.2 \times 0.8$ & EMR & Neuroendocrine tumor \\
\hline $59 / \mathrm{M}$ & Middle rectum & $1.5 \times 0.4$ & EMR & Tubular adenoma \\
\hline $68 / \mathrm{M}$ & Middle rectum & $1.7 \times 1.2$ & ESD & Tubulo-villous adenoma with HGD \\
\hline $77 / \mathrm{M}$ & Middle rectum & $1.8 \times 0.5$ & ESD & Invasive adenocarcinoma \\
\hline 21/F & Middle rectum & $3 \times 1.5$ & EMR & Inflammatory polyp \\
\hline $57 / M$ & Distal rectum & $1 \times 0.4$ & EMR & Tubulo villous adenoma \\
\hline $63 / \mathrm{M}$ & Middle rectum & $3 \times 1.7$ & EMR & Intramucosal carcinoma \\
\hline $36 / \mathrm{M}$ & Middle rectum & $1.2 \times 0.7$ & EMR & Neuroendocrine tumor \\
\hline $65 / \mathrm{M}$ & Middle rectum & $4 \times 1.9$ & ESD & Carcinoma in situ \\
\hline $36 / \mathrm{M}$ & Middle rectum & $2 \times 1.4$ & ESD & Intramucosal carcinoma \\
\hline $65 / \mathrm{M}$ & Middle rectum & $2 \times 1.3$ & Piecemeal EMR & Intramucosal carcinoma \\
\hline $67 / \mathrm{M}$ & Middle rectum & $3 \times 1.9$ & Piecemeal EMR & Tubulo-villous adenoma \\
\hline $47 / M$ & Distal rectum & $2 \times 1.3$ & EMR & Tubular adenoma \\
\hline $74 / \mathrm{F}$ & Distal rectum & $3 \times 1.3$ & Piecemeal EMR & $\begin{array}{c}\text { Tubulo-villous adenoma } \\
\text { with in situ carcinoma }\end{array}$ \\
\hline
\end{tabular}

HGD - high grade dysplasia, LGD - low grade dysplasia.

The follow-up period was 3 to 48 months. Computed tomography (CT) and/or PET-CT were used in follow-up of colonic lesion of patients who were diagnosed with invasive carcinoma. Magnetic resonance imaging (MRI), positron-emission tomography (PET) and transrectal endoscopic ultrasound (TRUS) 
were used in the follow-up of patients with rectal involvement who were diagnosed with an invasive carcinoma. With these imaging techniques, no distant metastases were found in any of the patients. Follow-up colonoscopy was performed at the $3^{\text {rd }}, 6^{\text {th }}$ and $12^{\text {th }}$ months to assess the location of polyps and lesions missed on visual inspection. Patients were then followed up with annual colonoscopy, CT, and $M R$ and there was no recurrence for 3-48 months.

\section{Discussion}

Endoscopically, precancerous adenomatous lesions and early carcinomas can be treated locally in the colon and rectum. The 5-year survival rate of stage 0 and stage I colon and rectum tumors treated with surgical resection was $94.3 \%$ and $90.6 \%$ respectively. The endoscopic cure rate was reported as $92.7 \%$. Both surgical and endoscopic treatment are satisfactory for both early stage tumors [6-8].

In order to determine the treatment strategy, accurate preoperative diagnosis of the lesions and appropriate treatment should be selected [9].

The correct approach and diagnosis should be assessed according to the morphologic appearance of the lesion according to the Paris classification, the Kudo classification using the indigo carmine and the lateral spreading characteristics [10, 11].

The EMR is a minimally invasive, easy to learn, safe technique, comfortable for the patient, with low cost, effectively used in the treatment of premalign lesions and early cancer, and with a low probability of lymph node metastasis. It was reported by Deyhle et al. in 1973 that in this commonly used technique the colon wall may be damaged during direct extraction with a sessile polyp by diathermy, but the complication rate of polypectomy can be reduced by saline injection into the submucosal space [12]. In this technique, injecting saline into the submucosal layer under the lesion to be removed will provide a fluid cushion between the mucosa and the muscle wall. This will alleviate the thermal effects on the colon wall and thus reduce the risk of complications.

Tumors with a horizontal growth pattern and a diameter larger than two centimeters are difficult to remove en bloc with piecemeal EMR $[13,14]$.

On the other hand, the recurrence rate after treatment with standard snare polypectomy and piecemeal EMR of tumors laterally spreading with colon polyps larger than $2 \mathrm{~cm}$ in various studies ranged from $2.7 \%$ to $14.3 \%$ [15].
There is no consensus on ESD standardization for colorectal lesions. Japanese and South Korean study groups suggest that ESD is appropriate treatment option for lesions more than $2 \mathrm{~cm}$ in size and early colorectal cancers in which en-bloc resection is difficult with snare EMR [16].

These tumors are nongranular and especially pseudodepressed lateral spreading type, possible lesions with submucosal infiltration, tumors with type $\mathrm{V}$ pit pattern, and enlarged lesions suspected of being malignant.

However, ESD has several drawbacks compared with conventional EMR, such as long operation time, high procedural complication rate, and technical difficulty in resection of colorectal tumors $[17,18]$.

Lesions in the colon are more difficult than lesions in the rectum due to the location of the lesion and the structure of the colon [19]. There are difficulties in the endoscopic resection of lesions located behind the haustra or angulated segment of the colon. In our study, the resection time of transverse colon lesions was longer than that of others.

Submucosal injections are used to raise the lesions to form a submucosal pad. Saline solutions are an ideal choice for short-term treatments. However, hyaluronic acid, glycerol, dextrose fluid, fibrinogen mixture and hydroxypropyl methylcellulose have recently been developed for long-term treatments [20-22]. We used hyaluronic acid because of the long duration of ESD in the rectum, whereas we used saline solution in short-term operations in which we performed EMR.

Because the colon wall is thinner than the stomach wall, the rate of complete en bloc resection and perforation of ESD is reported to be $4.8 \%$ (1.4-8.2\%) in the literature [23]. As the perforations are small, additional surgery is rarely necessary and in most cases clip and conservative treatment are adequate [14]. Some authors suggest piecemeal EMR, because of the high rate of perforation due to ESD in the colon. Postoperative bleeding was found in $1.5 \%(0.5-$ $9.5 \%)$ of patients on average $[21,24]$.

The surgical margin was positive in 2 out of $26 \mathrm{pa}-$ tients in our series (8.3\%). Transanal local excision was performed due to the lesions being localized in the rectum. The local recurrence rate is reported to be between $2.7 \%$ and $14.3 \%$ in the literature $[25,26]$. We have not experienced recurrence in the follow-up period of 3 to 48 months. We think that this is due to the low number of patients. It is reported in the literature that stage 0 and stage 1 tumors can be 
treated with local excision and chemotherapy and radiotherapy are not required for these patients. For more advanced tumors, surgery is recommended.

The advances in technology offer new instruments for endoscopic resections such as dual-channel endoscopes, endoscopes with large working channels and endoscopes with caps. Modalities such as magnification and chromoendoscopy used in colonoscopy help to establish an early diagnosis. Uraoka et al. reported using a double endoscope for ESD and EMR procedures in colon and rectum tumors [27]. Imaeda et al. reported using external forceps for retraction of the lesion during ESD [28]. In addition, there are methods such as band ligation to determine the border of the lesion and to provide internal traction [29].

\section{Conclusions}

Early diagnosis plays an important role in reducing mortality and morbidity in colorectal cancers. Early stage lesions diagnosed by polypectomy, ESD, and EMR are very important in terms of cost, patient comfort and complications.

\section{Conflict of interest}

The authors declare no conflict of interest.

\section{References}

1. Tada M, Shimada M, Yanai $H$, et al. New technique of gastric biopsy. I to Cho (Stomach and Intestine) 1984; 19: 1109-16.

2. Parada AA, Scarparo JIB, Santos CE. Terapêutica das lesões superficiais yapmak cólon e reto. içinde: Sociedade Brasileira de Endoscopia Digestiva. Endoscopia digestiva diagnóstica e terapêutica. Rio de Janeiro: Revinter 2005; 613-24.

3. Tamura S, Nakajo K, Yocoyama Y, et al. Evaluation of endoscopic mucosal resection for laterally spreading rectal tumors. Endos copy 2004; 36: 306-12.

4. Saito Y, Fujii T, Kondo H, et al. Endoscopic treatment of laterally spreading tumors in the colon. Endoscopy 2001; 33: 682-6.

5. Białek A, Wiechowska-Kozłowska A, Pertkiewicz J, et al. Endoscopic submucosal dissection for the treatment of neoplastic lesions in the gastrointestinal tract. World J Gastroenterol 2013; 19: 1953-61.

6. Saitoh Y, Taruishi M, Fujiya M, et al. Lymph node/distant metastasis and prognosis of colorectal SM carcinomas. Fron Colorectal Cancer 2008; 1: 133-7.

7. Watanabe T, Itabashi M, Shimada Y, et al. Japanese Society for Cancer of the Colon and Rectum (JSCCR) guidelines 2010 for the treatment of colorectal cancer. Int J Clin Oncol 2012; 17: 1-29.

8. Japanese Society for Cancer of the Colon and Rectum. MultiInstitutional Registry of Large Bowel Cancer in Japan. Cas- es treated in 1995-1998, vol. 17 (1999), [vol. 18 (2000), vol. 21 (2001), vol. 24 (2003)]

9. Tanaka S, Haruma K, Ito $M$, et al. Detailed colonoscopy for detecting early superficial carcinoma: recent developments. J Gastroenterol 2000; 35 (Suppl 12): S121-5.

10. The Paris endoscopic classification of superficial neoplastic lesions: esophagus, stomach, and colon: November 30 to December 1, 2002. Gastrointest Endosc 2003; 58 (6 Suppl): S3-43.

11. Kudo S, Kashida H, Nakajima T, et al. Endoscopic diagnosis and treatment of early colorectal cancer. World J Surg 1997; 21: 694-701.

12. Deyhle P, Largiader F, Jenny S, et al. A method for endoscopic electroresection of sessile colonic polyps. Endoscopy 1973; 5: 38-40.

13. Uraoka T, SaitoY, Matsuda T, et al. Endoscopic indications for endoscopic mucosal resection of laterally spreading tumors in the colorectum. Gut 2006; 55: 1592-7.

14. Saito Y, Fukuzawa M, Matsuda T, et al. Clinical outcome of endoscopic submucosal dissection versus endoscopic mucosal resection of large colorectal tumors as determined by curative resection. Surg Endosc 2010; 24: 343-52.

15. Santos CE, Malaman D, Pereira-Lima JC. Endoscopic mucosal resection in colorectal lesion: a safe and effective procedure even in lesions larger than $2 \mathrm{~cm}$ and in carcinomas. Arq Gastroenterol 2011; 48: 242-7.

16. Cunningham D, Atkin W, Lenzetal HJ. Colorectal cancer. Lancet 201; 375: 1030-47.

17. Ohkuwa M, Hosokawa K, Boku N, et al. New endoscopic treatment for intramucosal gastric tumors using an insulated-tip diathermic knife. Endoscopy 2001; 33: 221-6.

18. Gotoda T, Yamamoto H, Soetikno RM. Endoscopic submucosal dissection of early gastric cancer. J Gastroenterol 2006; 41: 929-42.

19. Imaeda H, Hosoe N, Kashiwagi K, et al. Advanced endoscopic submucosal dissection with traction. World J Gastrointest Endosc 2014; 6: 286-95.

20. Fujishiro M, Yahagi N, Nakamura M, et al. Successful outcomes of a novel endoscopic treatment for Gl tumors: endoscopic submucosal dissection with a mixture of highmolecular-weight hyaluronic acid, glycerin, and sugar. Gastrointest Endosc 2006; 63: 243-9.

21. Hirasaki S, Kozu T, Yamamoto H, et al. Usefulness and safety of $0.4 \%$ sodium hyaluronate solution as a submucosal fluid 'cushion' for endoscopic resection of colorectal mucosal neoplasms: a prospective multi-center open-label trial. BMC Gastroenterol 2009; 9: 1.

22. Tanaka S, Terasaki M, Kanao H, et al. Current status and future perspectives of endoscopic submucosal dissection for colorectal tumors. Dig Endosc 2012; 24 (Suppl. 1): 73-9.

23. Yandrapu H, Desai M, Siddique $S$, et al. Normal saline solution versus other viscous solutions for submucosal injection during endoscopic mucosal resection: a systematic review and metaanalysis. Gastrointest Endosc 2017; 85: 693-9.

24. Luigiano C, Consolo P, Scaffidi MG, et al. Endoscopic mucosal resection for large and giant sessile and flat colorectal polyps: a single-center experience with long-term follow-up. Endoscopy 2009; 41: 829-35. 
25. Yoshida N, Naito Y, Murakami T, et al. High incidence of postoperative hemorrhage in colorectal endoscopic submucosal dissection during anticoagulant therapy. Int J Colorectal Dis 2016; 31: 1487-8.

26. Hurlstone DP, Fu KI, Brown SR, et al. EMR using dextrose solution versus sodium hyaluronate for colorectal Paris type I and 0-II lesions: a randomized endoscopist-blinded study. Endoscopy 2008; 40: 110-4.

27. Uraoka T, Ishikawa S, Kato J, et al. Advantages of using thin endoscope-assisted endoscopic submucosal dissection technique for large colorectal tumors. Dig Endosc 2010; 22: 186-91.

28. Imaeda H, Hosoe N, Ida Y, et al. Novel technique of endoscopic submucosal dissection by using external forceps for early rectal cancer (with videos). Gastrointest Endosc 2012; 75: 1253-7.

29. Takeda T, Murakami T, Sakamoto N, et al. Traction device to remove an adenoma in the appendiceal orifice by endoscopic submucosal dissection. Endoscopy 2013; 45 Suppl 2 UCTN: E239-40.

Received: 17.06.2018, accepted: 16.08.2018. 